\title{
Winter syndrome: about an uncommon case report
}

\author{
Aziz Slaoui ${ }^{1,2^{*}}$, Sarah Talib², Abdelali Kallali', Mariem Rouijel ${ }^{1}$ and Aziz Baydada ${ }^{1}$
}

\begin{abstract}
Background: Congenital genital tract outflow obstruction may occur at different levels and with different clinical presentations. Winter syndrome was first described in 1968 as an association of renal, genital and middle ear anomalies. This syndrome is characterized by autosomal recessive transmission, unilateral or bilateral renal hypoplasia, distal vaginal atresia, and moderate to severe conductive hearing loss with malformation of the ossicles. The diagnosis is usually made when symptoms of obstruction are obvious. It presents most commonly with primary amenorrhea in a girl with a normal XX genotype, ovarian and hormone function; and cyclical abdominal pain. Ultrasound confirm the physical examination, revealing the presence of a normal uterus and cervix, normal ovaries and fallopian tubes, and a large hematocolpos.

Case presentation: This case reports Winter syndrome in a 14-year-old girl which vaginal atresia was managed by a trans perineal vaginal pull through.

Conclusions: Winter syndrome is a rare congenital condition whose clinical picture is that of an adolescent girl with primary amenorrhea and cyclic pelvic pain due to vaginal atresia, varying degrees of renal dysgenesis and deafness due to malformation of the ossicles of the middle ear. Diagnosis is based on clinical examination and imaging. Magnetic resonance imaging allows assessing the importance of atresia and thus guiding surgical management. The goals of surgical intervention are to provide relief from pain, ensure normal sexual intercourse and to preserve fertility. A thorough knowledge of embryology, pre-operative imaging with MRI and clinical examination is essential to plan an appropriate surgical management.
\end{abstract}

Keywords: Vaginal aplasia, Poly malformative syndrome, Winter syndrome

\section{Background}

Distal vaginal agenesis has been described in association with a variety of anomalies. Winter et al. described the association of vaginal atresia, renal aplasia or hypoplasia and anomalies of the ossicles of the middle ear in women with normal development of secondary sexual characteristics and a 46, XX karyotype [1]. Radiographic features may show a hydrometrocolpos or hematometrocolpos due to

\footnotetext{
*Correspondence: azizslaoui27@gmail.com

${ }^{1}$ Gynaecology-Obstetrics and Endoscopy Department, Maternity Souissi, University Hospital Center IBN SINA, University Mohammed V, Rabat, Morocco

${ }^{2}$ Gynaecology-Obstetrics and Endocrinology Department, Maternity Souissi, University Hospital Center IBN SINA, University Mohammed V, Rabat, Morocco
}

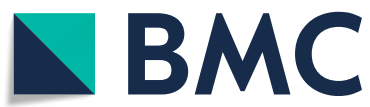

(c) The Author(s). 2020 Open Access This article is licensed under a Creative Commons Attribution 4.0 International License, which permits use, sharing, adaptation, distribution and reproduction in any medium or format, as long as you give appropriate credit to the original author(s) and the source, provide a link to the Creative Commons licence, and indicate if changes were made. The images or other third party material in this article are included in the article's Creative Commons licence, unless indicated otherwise in a credit line to the material. If material is not included in the article's Creative Commons licence and your intended use is not permitted by statutory regulation or exceeds the permitted use, you will need to obtain permission directly from the copyright holder. To view a copy of this licence, visit http://creativecommons.org/licenses/by/4.0/ The Creative Commons Public Domain Dedication waiver (http://creativecommons.org/publicdomain/zero/1.0/) applies to the data made available in this article, unless otherwise stated in a credit line to the data.

\section{Case presentation}

We hereby report an uncommon case of a 14-year-old girl, living in a rural area, being first child of two siblings, with a younger brother having no significant pathology, and whose parents are second degree consanguineous. She was born from a full-term pregnancy without significant incident, exposure to radiation or maternal drugs, except for vitamins and iron. Her vaginal delivery in a birth center was without notable incidents, placental

obstruction [2]. The proper diagnosis and management of this pathology demands a rigorous knowledge of the relevant embryology, anatomy and physiology as well as sensitivity to the psychological effects of the condition. 
examination was normal, but the search for a single umbilical artery was not mentioned.

At 14-year-old, she was admitted at our tertiary care center with complaints of primary amenorrhea and cyclical lower abdominal pain evolving for six months. Clinical examination revealed a normal morphotype, a correct size, well-developed secondary sex characteristics and breast and pubic hair were categorized as Tanner stage 5 and Marshall stade 3 [3]. A mobile nontender mass, arising from the pelvis to the belly button, was felt in the abdomen. Vulvo-perineal inspection revealed clitoral hypertrophy, labia hypoplasia and the absence of an external vaginal opening (Fig. 1). On rectal examination, a tense cystic mass suggestive of hematocolpos was felt anteriorly. An ENT consultation revealed the normal morphology of the pavilions as well as the external auditory canals, however, severe transmission hypoacousia of the right ear with a hearing loss of $70 \mathrm{~dB}$ was noted. Abdominal-pelvic ultrasound showed hematocolpos proximal to the perineum and hematometra with an otherwise normal-appearing uterus and ovaries. It also revealed the presence of a small dedifferentiated atrophic right kidney associated with compensatory hypertrophy of the contralateral left kidney. Hormonal assays were performed and within normal range. $\mathrm{FSH}, \mathrm{LH}$, and 17b estradiol were normal. Testosterone, D4 androstenedione, $17 \mathrm{OH}$ progesterone and DHEA were also normal, which allowed us to eliminate hyperandrogenism. Renal function tests were normal and reflected an effective compensation of the left kidney. The blood karyotype

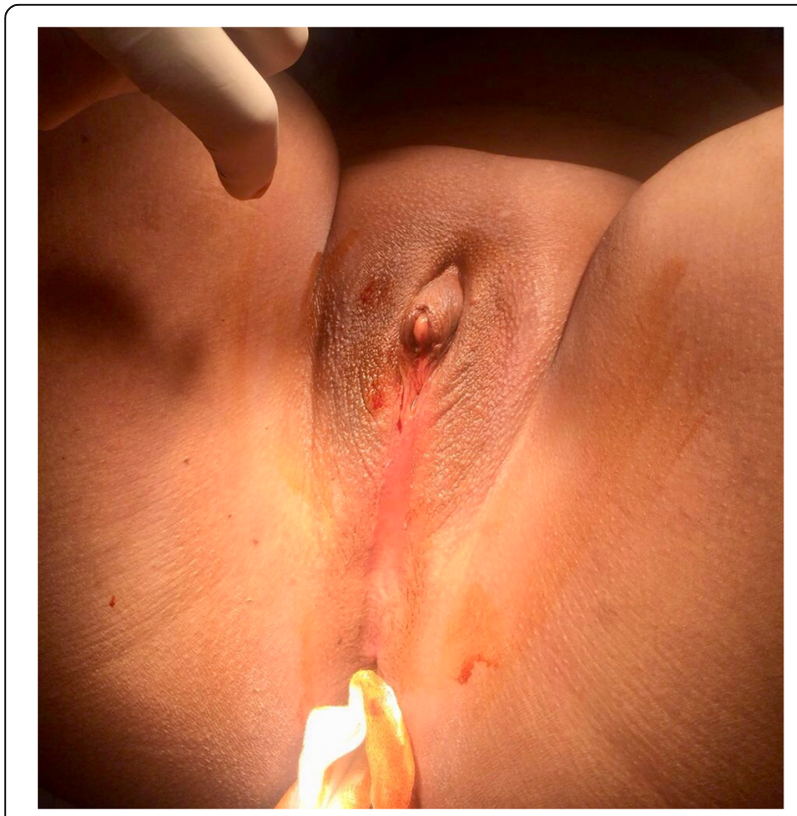

Fig. 1 Vulvo-perineal inspection of the clitoral enlargement with hypoplasia of the labia and absence of an external vaginal opening was also normal (46 XX), with no visible chromosomal abnormality.

The diagnosis of poly malformative syndrome associating vaginal, renal and auditory involvement was therefore retained, also called Winter syndrome. A multidisciplinary consultation meeting allowed to opt for a reconstructive surgery of her vaginal agenesis associated with a close monitoring of her auditory and renal functions. Before surgical treatment, the patient and her family were informed about the prognosis of her fertility and verbal as well as written consent were obtained from her legal guardian.

The vaginoplasty was then carried out with the patient in the dorsal lithotomy position. A Foley catheter is placed into the bladder to avoid an inadvertent anterior entry into the posterior wall of the bladder. A transverse incision is made where the introitus should be located, and a dissection is carried out to reach the obstructed upper vaginal tissue. Care is needed to keep the dissection in the midline and avoid the bladder above and the rectum below (Fig. 2). Creation of a $5 \mathrm{~cm}$-length passage through connective tissue was done carefully to reach the tense bulge of the hematocolpos and allow drainage. Mucosal margins of the upper vagina were then pulled down till the introitus and sutured there with a spacing of 5 $\mathrm{mm}$ between each suture, in a radial arrangement (Figs. 3 and 4). The mobilization of the dilated proximal vagina allowed the pull-through vaginoplasty. Operative time was $126 \mathrm{~min}$ and blood loss were quantified at $200 \mathrm{ml}$. Prophylactic antibiotics were initiated postoperatively.

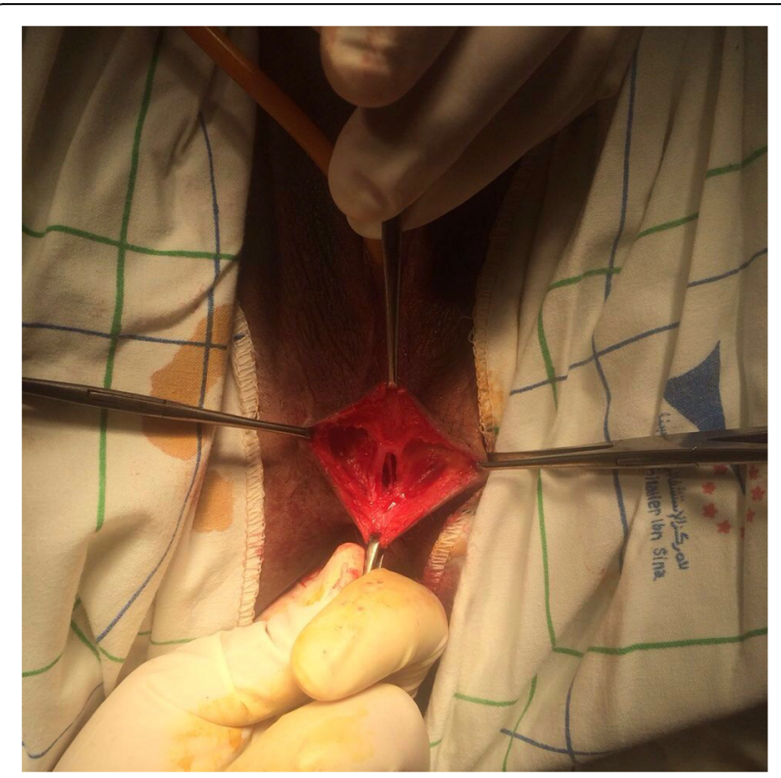

Fig. 2 Per operative image of the dissection in the midline to avoid the bladder above and the rectum below 


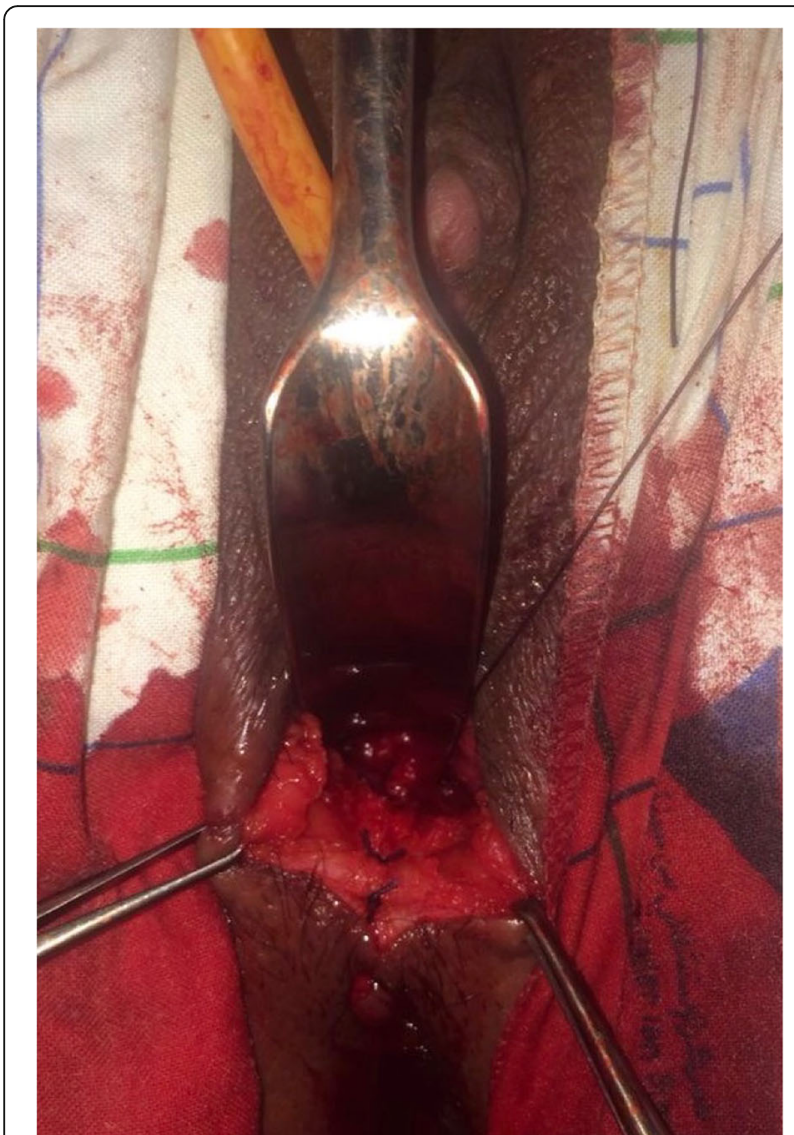

Fig. 3 Per-operative image of the neovagina's radial sutures

After a successful surgery, we guided the patient on the use of vaginal mold to ensure that the vagina heals well without restenosis. The opening of the vaginal introit was then dilated by ascending vaginal probes of increased dimensions lubricated with estrogen gel, until complete healing and sufficient caliber to sexual intercourse. On follow-up after 2 months, she was regular menstruating with no obstruction signs. At 20-year-old, the young woman became pregnant, and safely vaginally delivered a healthy male baby weighting $2700 \mathrm{~g}$ at 38 weeks' gestation without an episiotomy.

\section{Discussion and conclusions}

Vaginal atresia is a rare congenital anomaly with an incidence ranging from 1 in 4000 to 1 in 10,000 females [4]. It occurs when the urogenital sinus fails to form the distal portion of the vagina, which is replaced with fibrous tissue resulting in utero-vaginal outflow tract obstruction [5]. This genital tract outflow is important for secretion and menstrual effluxion and as a pathway in reproductive function. It may occur as an isolated defect or more commonly associated with various syndromes $[6,7]$. Mayer-Rokitansky-Kuster, Kaufman-McKusick, Fraser, Winter and congenital adrenal hyperplasia

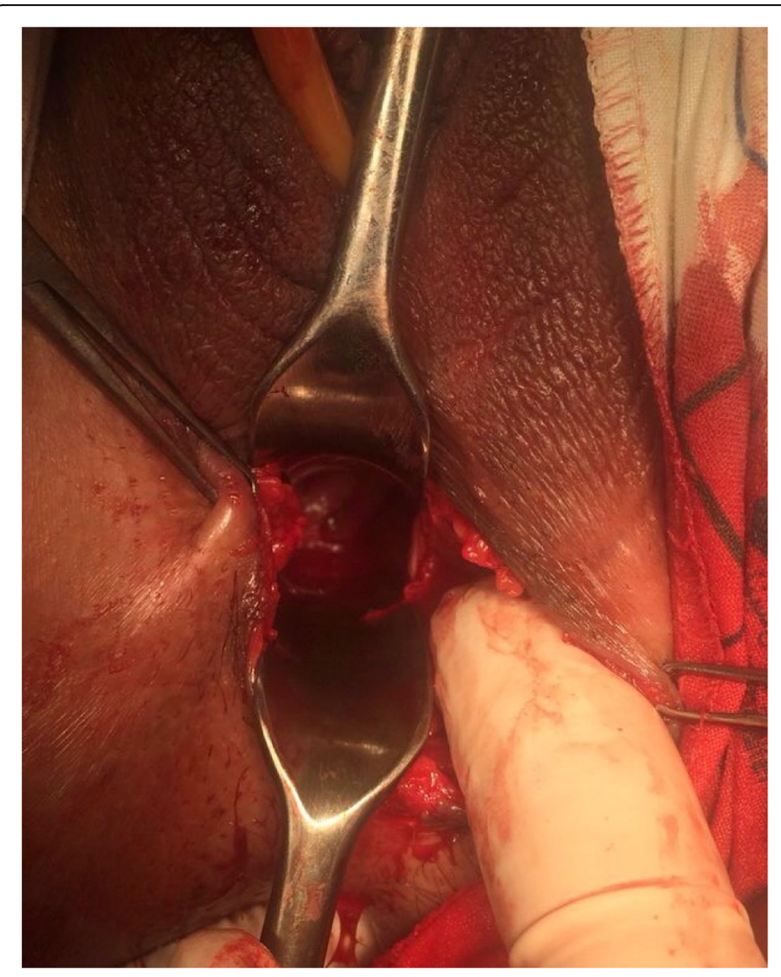

Fig. 4 Per-operative image of the neovagina with the cervix external orifice

syndromes are the known examples of such associations [8]. A relatively constant element of these malformations is the association of abnormalities of the genital tract and the urinary system. The embryogenesis of these two systems being intimately linked [9]. In 1941, Gruenwald demonstrated that resection of the Wollfian duct resulted in absent kidney and fallopian tube and unicornuate uterus [10].

Vaginal atresia in Winter syndrome is a distinct condition from vaginal agenesis which is most commonly encountered in women with Rokitansky syndrome (MayerRokitansky-Kuster-Hauser syndrome or Müllerian aplasia) [11]. MRKH syndrome is characterized by a congenital absence of the upper vagina and uterus in a phenotypically, chromosomally and hormonally intact female. While in Winter syndrome, the upper vagina and female reproductive structures are intact, because the differentiation of Mullerian organs is unaffected [8, 12]. Moreover, while Müllerian aplasia confers irreversible sterility, vaginal atresia can be surgically corrected to permit pregnancy [13].

Literature review has allowed us to find five cases of winter syndrome including its first description. In 1968, Winter et al. [1] described a family of four sisters who showed varying degrees of renal dysgenesis, deafness due to malformation of the ossicles of the middle ear, and vaginal atresia [1]. Turner et al's reported in 1970 a 
family of four sisters with the eldest one who presented with an abnormal face with a very narrow external auditory meatus with mild deafness associated with absent right kidney and vaginal atresia [14]. The authors suggested that this syndrome might be a recessive disease possibly lethal in the male. McKusick et al's listed in 1986 the condition as likely autosomal recessive, assigning the number 267400 for his catalog and referenced also Schmidt et al's report [15-17]. In another family described by King et al. [13] in 1987, one of two affected siblings delivered a normal female infant after vaginal reconstructive surgery. Our patient also delivered a healthy female infant vaginally. Affected siblings and parental consanguinity suggest autosomal recessive inheritance [1, 13]. Franck et al. described in 1982 a small female with clitoral enlargement, hypoplasia of the labia minora, aplasia of the kidney and sensorineural hearing loss [18]. This review of the literature allowed us to note that the Winter syndrome can take on a myriad of presentations. First, renal malformations can lead to renal agenesis as in the case presented by Winter et al. but can also be associated with a bladder hemiatrophy found in the report by Turner et al. [1, 14]. Similarly, auditory malformations mainly concern the middle ear but can also be associated with malformations of the outer ear or even of the face [14]. Growth restriction is also a non-systematic but recurrent symptom, found in 3 out of $5[1,14,18]$. Finally, we note the presence of associated rectal malformation found in a single case presented by Turner et al's [14].. All this leads us to suggest that the Winter syndrome is an entity in its own right, most certainly of autosomal recessive transmission, whose very low recurrence prevents us from fully understanding nor determine the responsible genetic anomaly [17].

Diagnosis can occur at any time; however, most cases are diagnosed in adolescence upon primary amenorrhea and cyclic lower abdominal pain [19]. The clinical picture is that of a girl of pubertal age who consults for primary amenorrhea, whose normo-hormonal character is evident [7]. Anamnesis raises the notion of cyclic chronic pelvic pain [20]. Clinical examination finds a normal morphotype with appropriate Tanner's staging of secondary sex characteristics [3]. Examination of the perineum reveals absence of vaginal opening [19]. The obstruction can lead to heamatometra, heamatocolpos, endometriosis or pyometra [20]. Trans-abdominal or trans-perineal ultrasound may specify the level of the obstacle [2, 21]. Pelvic ultrasound confirms the diagnosis. It objectifies the image of an hematometra with functional ovaries containing follicles. Transrectal ultrasound can help to analyze the cervix because it provides a precise view of the pelvic organs [22]. Renal ultrasound or intravenous urography will look for an associated urinary malformation [23]. Currently, MRI scanning appears to be the most reliable examination for the diagnosis [24]. It can specify better the height and extent of vaginal aplasia thus making it possible to guide the choice of the most appropriate surgical technique [25].

In our patient, both ovaries with fallopian ducts, uterus, and upper $2 / 3 \mathrm{rd}$ of vagina were normal, therefore, we concluded it to be a urogenital sinus anomaly. She also had a conductive hearing loss and an atrophic right kidney which led us to the diagnosis of Winter syndrome. Therapy is directed to relieve the obstruction of the vaginal outlet and provide normal sexual life and reproductive function [26]. Unlike Rokitansky's syndrome, vaginoplasty in winter syndrome can allow pregnancy [13]. The management when the atretic segment does not exceed $3 \mathrm{~cm}$ is simple. It is done by direct anastomosis of the vaginal mucosa. In contrast, surgery of extended forms is more complex. It uses cutaneous or intestinal grafts [27].

Prophylactic antibiotics initiated postoperatively are important with pull-through vaginoplasty, because the uterus and fallopian tubes may contain blood which is an excellent growth media and because there is a risk of bacteria ascending into what becomes an open system [28]. Postoperatively, the use of dilators ensures that the vagina heals without restenosis [29]. With adequate postoperative dilation, patients will have normal sexual and reproductive function, and vaginal delivery should be possible [30-32]. Our patient was managed successfully by a perineal approach. Symptoms were then relieved, menstrual function was retained and functional vagina was formed.

Winter syndrome is a rare congenital condition whose clinical picture is that of an adolescent girl with primary amenorrhea and cyclic pelvic pain due to vaginal atresia, varying degrees of renal dysgenesis and deafness due to malformation of the ossicles of the middle ear. Diagnosis is based on clinical examination and imaging. Magnetic resonance imaging allows assessing the importance of atresia and thus guiding surgical management. Therapy is directed to relieve the obstruction of the vaginal outlet and provide normal sexual life and reproductive function.

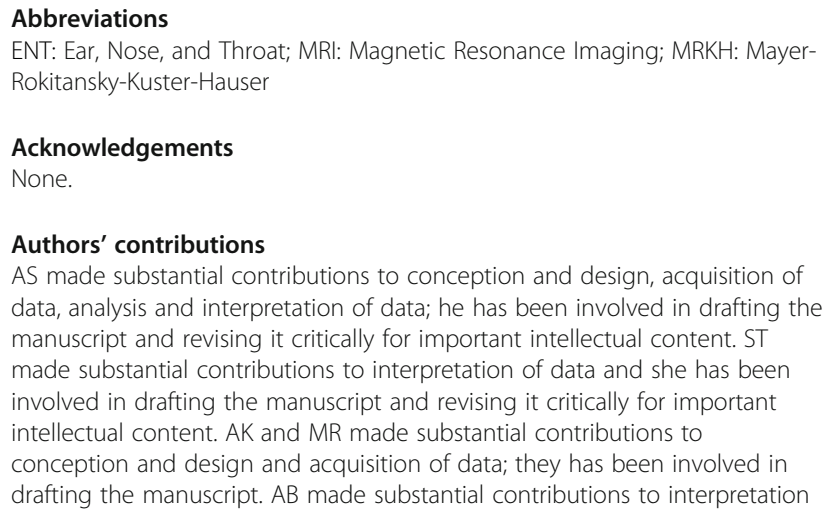


of data; he has been involved in revising it critically for important intellectual content. All authors read and approved the final manuscript.

\section{Funding}

There are no funding sources to be declared.

\section{Availability of data and materials}

The datasets used and/or analyzed during the current study are available from the corresponding author on reasonable request.

\section{Ethics approval and consent to participate}

Ethics approval has been obtained to proceed with the current study.

Consent to participate not applicable.

\section{Consent for publication}

Written informed consent was obtained from the patient's parent/guardian for publication of this case report and any accompanying images. A copy of the written consent is available for review by the Editor-in-Chief of this journal.

\section{Competing interests}

The authors declare that they have no competing interests.

Received: 5 September 2019 Accepted: 15 April 2020

Published online: 21 April 2020

\section{References}

1. Winter JSD, Kohn G, Mellman WJ, Wagner S. A familial syndrome of renal, genital and middle ear anomalies. J Pediatr. 1968;72:88-93.

2. Valdes C, Malini S, Malinak LR. Ultrasound evaluation of female genital tract anomalies: a review of 64 cases. Am J ObstetGynecol. 1984;149:285-90.

3. De Sanctis V, Elhakim IZ, Soliman AT, Elsedfy H, Elalaily R, Millimaggi G. Methods for rating sexual development in girls. Pediatr Endocrinol Rev. 2016;14(1):27-32

4. Evans TN, Poland ML, Boving RL. Vaginal malformations. Am J ObstetGynecol. 1981;141(8):910-20.

5. Ozturk H, Yazici B, Kucuk A, DA. Senses Congenital imperforate hymen with bilateral hydronephrosis, polydactyly and laryngocele: A rare neonatal presentation. Fetal Pediatr Pathol. 2010;29:89-94.

6. Junqueira BLP, Allen LM, Spitzer RF, et al. Müllerian duct anomalies and mimics in children and adolescents: correlative intraoperative assessment with clinical imaging. Radiographics. 2009;29(4):1085-103.

7. Vallerie AM, Breech LL. Update in Müllerian anomalies: diagnosis, management, and outcomes. Curr Opin Obstet Gynecol. 2010;22:381-7.

8. Sultan C, Biason-Lauber A, Philibert P. Mayer-Rokitansky-Kuster-Hauser syndrome: recent clinical and genetic findings. Gynecol Endocrinol. 2009;25: $8-11$

9. Morcel K, Camborieux L. Mayer-Rokitansky-Kuster-Hauser (MRKH) syndrome. Orphanet J Rare Dis. 2007;2:13.

10. Gruenwald P. The relation of the growing Mullerian duct and the Wolffian duct and its importance for the genesis of malformations. Anat Rec. 1941; 81:1-19.

11. Herlin M, Bjørn AM, Rasmussen M, et al. Prevalence and patient characteristics of Mayer-Rokitansky-Küster-Hauser syndrome: a nationwide registry-based study. Hum Reprod. 2016;31:2384-90.

12. Strubbe EH, Willemsen WN, Lemmens JA, Thijn CJ, Rolland R. MayerRokitansky-Kuster-Hauser syndrome: distinction between two forms based on excretory urographic, sonographic, and laparoscopic findings. AJR Am Roentgenol. 1993;160:331-4.

13. King LA, Sanchez-Ramos L, Talledo OE, Reindollar RH. Syndrome of genital, renal, and middle ear anomalies: a third family and report of a pregnancy. Obstet Gynecol. 1987;69:491-3.

14. Turner G. A second family with renal, vaginal, and middle ear anomalies. J. Pediat. 1970;76:641.

15. McKusick VA. Mendelian Inheritance in Man. www.OMIM.org. Accessed February 25, 2020

16. Schmidt ECH, Hartley AA, Bower R. Renal aplasia in sisters. Arch Path. 1952 54:403-6.

17. Lebel, R. R. (2018). 50 years ago in the journal of pediatrics. The Journal of Pediatrics, 192, 129. doi:https://doi.org/10.1016/j.jpeds.2017.07.042.
18. Franck A. An Oto-Uro-genital syndrome with microsomia. Monatshr kinderheilkd. 1982;130:731-3.

19. Jones HW Jr, Wheeless CR. Salvage of the reproductive potential of women with anomalous development of the müllerian ducts: 1868-1968-2068. Am J Obstet Gynecol. 1969;104:348-64.

20. Kelly GS, Baluyot MF, Anders JF. Cyclical abdominal pain in an adolescent female : A case report of agenesis of the lower vagina. Pediatr Emerg Care. 2018;34(7):136-8.

21. Graham D, Nelson MW. Combined perineal-abdominal sonography in the evaluation of vaginal atresia. J Clin Ultrasound. 1986;14:735-8.

22. Fedele L, Portuese A, Bianchi S, et al. Transrectal ultrasonography in the assessment of congenital vaginal canalization defects. Hum. Reprod. 1999; 14:359-62.

23. Doganay S, Yikilmaz A, Kahriman G, et al. Medical image. Haematometrocolpos secondary to vaginal atresia: US and MRI findings. N. Z. Med. J. 2010;123(1309):114-6.

24. Rall $K$, Eisenbeis $S$, Henninger $V$, Henes $M$, Wallwiener $D$, Bonin $M$, et al, Typical and atypical associated findings in a group of 346 patients with Mayer-Rokitansky-Kuester-Hauser syndrome. J Pediatr Adolesc Gynecol. 2015:28:362-8.

25. Hricak H, Chang YCF, Thurnher S. Vagina: evaluation with MR imaging. Part I: Normal anatomyand congenital anomalies. Radiology. 1988:169:169-74.

26. Mclndoe A. The treatment of congenital absence and obliterative conditions of the vagina. Br J Plast Surg. 1950;2:254-67.

27. Ugur M, Balat O, Ozturk E, Bekerecioglu M, Dikensoy E. Pitfalls in diagnosis and management of distal vaginal agenesis: 10-year experience at a single Centre. Eur J Obstet Gynecol Reprod Biol. 2012;163:85-90.

28. Mansouri R, Dietrich JE. Postoperative course and complications after pullthrough Vaginoplasty for distal vaginal atresia. J Pediatr Adolesc Gynecol. 2015;28(6):433-6.

29. Wiser WL, Bates GW. Management of agenesis of vagina. Surg Gynecol Obstet. 1984;159:108-12.

30. Singh J, Devi YL. Pregnancy following surgical correction of nonfused müllerian bulbs and absent vagina. Obstet Gynecol. 1983;61:267-9.

31. Chakravarty B, Konar $\mathrm{H}$, Chowdhury NN. Pregnancies after reconstructive surgery for congenital cervicovaginal atresia. Am J Obstet Gynecol. 2000; 183:421-3.

32. Wesley JR, Coron AG, Michigan AA. Intestinal vaginoplasty for congenital absence of vagina. J Pediatr Surg. 1992;27:885-9.

\section{Publisher's Note}

Springer Nature remains neutral with regard to jurisdictional claims in published maps and institutional affiliations.

Ready to submit your research? Choose BMC and benefit from:

- fast, convenient online submission

- thorough peer review by experienced researchers in your field

- rapid publication on acceptance

- support for research data, including large and complex data types

- gold Open Access which fosters wider collaboration and increased citations

- maximum visibility for your research: over $100 \mathrm{M}$ website views per year

At BMC, research is always in progress.

Learn more biomedcentral.com/submissions 